\title{
Urbanization and the Rise of Vector Mosquitoes and Arbovirus Transmission ${ }^{\dagger}$
}

\author{
André B. B. Wilke ${ }^{1, *}$, Giovanni Benelli ${ }^{2}$, John C. Beier ${ }^{1}$
}

Citation: Wilke, A.B.B.; Benelli, G.; Beier, J.C. Urbanization and the Rise of Vector Mosquitoes and Arbovirus Transmission, in Proceedings of the 1st International Electronic Conference on Entomology, 1-15 July 2021, MDPI: Basel, Switzerland, doi:10.3390/IECE-10501

Published: 1 July 2021

Publisher's Note: MDPI stays neutral with regard to jurisdictional claims in published maps and institutional affiliations.

Copyright: (c) 2021 by the authors. Submitted for possible open access publication under the terms and conditions of the Creative Commons Attribution (CC BY) license (http://creativecommons.org/licenses /by/4.0/).

\author{
${ }^{1}$ Department of Public Health Sciences, Miller School of Medicine, University of Miami, Miami, FL, United \\ States of America \\ 2 Department of Agriculture, Food and Environment, University of Pisa, via del Borghetto 80, 56124 Pisa, Italy \\ *Correspondence: author: André B. B. Wilke, Department of Public Health Sciences, Miller School of Medicine, \\ University of Miami, Miami, FL, USA, 1120 Northwest 14th Street, Miami, Florida, 33136. E-mail: \\ axb1737@med.miami.edu \\ + Presented at the 1st International Electronic Conference on Entomology (IECE 2021), 1-15 July 2021; \\ Available online: https://iece.sciforum.net/.
}

\begin{abstract}
The transformation of natural environments into urban areas has been on the rise since the industrial revolution in the late 1800s. Currently, urbanization is a global phenomenon intended to accommodate the natural growth of the human population as well as to the increasing levels of migration from rural to urban areas. Urbanization processes are responsible for levels of biodiversity loss never seen since the dawn of human civilization. In this context, the few species that can exploit the resources available in urban areas can greatly benefit and proliferate in those areas mainly by the virtual absence of natural predators and the overabundance of resources as a result of the biotic homogenization process. These few species that are able to thrive in urban environments alongside humans are commonly known as urban exploiters. Aedes aegypti and Culex quinquefasciatus are among those few species that can thrive in urban environments and, as a consequence, have considerably expanded not only their range but also their abundance in many cities of the world. They are currently present in most large cities in tropical and sub-tropical regions of the world. This represents a considerable public health challenge since Ae. aegypti and Cx. quinquefasciatus are some of the most epidemiologically relevant mosquito species. Aedes aegypti is a primary vector of chikungunya, dengue, yellow fever, and Zika viruses, whereas Cx. quinquefasciatus is a primary vector of West Nile, Eastern Equine encephalitis, and Saint Louis Encephalitis viruses. New mosquito surveillance and control strategies are needed to deal with this increasing threat of arboviruses outbreaks in urban areas.
\end{abstract}

Keywords: Mosquito; arbovirus; vector control; dengue virus; Zika virus; West Nile virus 